negative patients. Amaurosis was found in 7 patients; complete visual loss developed in one case.

Acute uveitis was seen only among arthritis+enthesitis patients $(\mathrm{n}=6 ; 10.7 \%)$ and in patients with other arthritis $(\mathrm{n}=$ 2; 14,3\%).

Conclusion Uveitis is relatively common in JIA. Chronic form may occur in several JIA subgroups, with persistent oligoarthritis patients and, surprisingly, with psoriatic arthritis patients being the most frequently affected. Acute uveitis is associated with HLA B27 associated disease forms. It is important to check for asymptomatic uveitis through the entire course of disease, as it may begin well after the onset of arthritis and may lead to severe complications.

Supported by grant NE/4879-3 from IGA of the Czech Ministry of Health.

\section{SAT0109 EXPRESSION OF BCL-2 IN JUVENILE CHRONIC ARTHRITIS}

${ }^{1}$ E Tuszkiewicz-Misztal, ${ }^{2} \mathrm{~A}$ Bojarska-Junak, ${ }^{2} \mathrm{P}$ Krawczyk, ${ }^{2} \mathrm{~J}$ Roliñski, 'V Opoka-Winiarska. ${ }^{1}$ Department of Paediatrics, Pulmonary Diseases and Rheumatology; ${ }^{2}$ Department of Clinical Immunology, Medical University, Lublin, Poland

\subsection{6/annrheumdis-2001.502}

Background The aim of this study was to investigate the relationship between levels of molecules regulating of apoptosis in $\mathrm{T}$ lymphocytes and the clinical manifestation of juvenile chronic arthritis (JCA).

Objectives Apoptosis is involved in the regulation of an immune response to foreign and autoantigens. We determined the expression of Bcl-2 mitochondrial oncoprotein, which inhibit apoptosis, in different subtypes of lymphocytes obtained from peripheral blood from healthy children $(\mathrm{n}=14$, age:12,4 \pm $5,4)$ and JCA patients with pauciarticular onset ( $\mathrm{n}=17$, age: $12,2 \pm 3,8)$ and polyarticular onset $(\mathrm{n}=30$, age: $11,8 \pm 3,2)$.

Methods All samples were analysed using monoclonal antibodies and flow cytometry technique.

Results Peripheral blood T lymphocytes from patients with pauciarticular onset JCA expressed a significantly lower amount of the $\mathrm{Bcl}-2$ protein than $\mathrm{T}$ lymphocytes from patients with polyarticular onset JCA $(\mathrm{p}<0,01)$ and healthy children $(\mathrm{p}<0,05)$. This differences concerned both $\mathrm{CD}^{+}$and $\mathrm{CD}^{+} \mathrm{T}$ cells but $\mathrm{CD} 4^{+}$lymphocytes expressed significantly $(\mathrm{p}<0,05)$ lower level of $\mathrm{Bcl}-2$ protein in comparison with $\mathrm{CD}^{+}$cells in patients with polyarticular onset JCA. There were no correlations between the expression of $\mathrm{Bcl}-2$ and the age of children in all subgroup of patients. There was significant positive correlation $(\mathrm{R}=0,562, \mathrm{p}<0,05)$ between the percentage of $\mathrm{T}$ lymphocytes with receptor for IL-2 (CD25) and expression of Bcl-2 protein in T cells in children with pauciarticular onset JCA.

Conclusion Our data supported the notion that disturbances in T cell apoptosis may play a role in the immunopathological processes leading to clinical manifestation of JCA, These data suggest also that both polyarticular onset and pauciarticular onset JCA have different pathogenesis and probably distinct aetiologies.
SAT0110 SOLUBLE ADHESION MOLECULES (ICAM-1, VCAM-1, ESELECTIN, P-SELECTIN) IN JUVENILE IDIOPATHIC ARTHRITIS AND CHILDHOOD - ONSET SCLERODERMA

${ }^{1}$ EK Musiej-Nowakowska, ${ }^{2}$ Sopata, ${ }^{2} \mathrm{~J}$ Wize, ${ }^{2} E$ Wojtecka-Lukasik, ${ }^{1} \mathrm{~A}$ Romicka, ${ }^{2} \mathrm{~S}$ Maslinski. 'Pediatric Clinic; ${ }^{2}$ Department of Biochemistry, Institute of Rheumatology, Warsaw, Poland

\subsection{6/annrheumdis-2001.503}

Background The soluble forms of adhesion molecules (sAM) may have a regulatory function in inflammatory responses and may serve as useful markers of both leukocyte and endothelial cells activation in different diseases, including several autoimmune disorders. They have been studied in adults with certain rheumatic diseases while studies in paediatric patients are more limited.

Objectives The aim of this study was to compare the levels of sAM in children with juvenile idiopathic arthritis (JIA) and scleroderma and to correlate serum levels of these molecules with conventional inflammatory parameters and to determine differences in these levels among clinical subtypes of JIA.

Methods Soluble forms of AM ICAM-1, VCAM-1, E-selectin and P-selectin were measured by sandwich ELISA in 47 children with JIA, (24 pauciarticular, 7 polyarticular, 16 systemic) and 11 patients with scleroderma. The levels of sAM according to type of disease, JIA type and some inflammatory parameters (ESR, total white blood cell count-WBC, platelet count) were analysed. Results Differences in serum levels of sAM have been demonstrated among the 3 subtypes of JIA. The highest values were seen in patients with systemic disease, lower values in patients with polyarthritis and pauciarticular form. The statistically significant higher levels of sICAM-1 $(\mathrm{p}<0.01)$ and sE-selectin $(\mathrm{p}<$ 0.05 ) were recorded only in JIA patients with systemic symptoms than in children who were pauciarticular. In systemic JIA, positive correlation was found between sICAM-1 as well as $\mathrm{sE}$ selectin levels and ESR and WBC. Levels of sICAM-1 and sEselectin were significantly higher in children with abnormal values of ESR versus patients with normal values $(p<0.05$ and $p$ $<0.05$, respectively). Similarly, significantly higher levels of sICAM-1, sE-selectin and sP-selectin were recorded in cases with higher number of WBC in comparison with others $(\mathrm{p}<0.05$, $\mathrm{p}$ $<0.025, \mathrm{p}<0.02$, respectively). In patients with scleroderma sE-selectin level was lower than in polyarticular form $(p<0.05)$ and the concentration of both sICAM-1 and sE-selectin were significantly lower than in systemic JIA ( $\mathrm{p}<0.05$ and $\mathrm{p}<0.05$, respectively). In contrast, sVCAM-1 levels were significantly higher only in scleroderma children in comparison with pauciarticular $(\mathrm{p}<0.02)$ and higer than in polyarticular and equal to the systemic group.

Conclusion The preliminary results indicate the role of sVCAM1 in the pathogenesis of childhood-onset scleroderma and confirm the differences between subtypes of JIA and suggest that sICAM-1 and sE-selectin may be another useful tool of monitoring the activity of systemic JIA.

\section{SAT0111 JUVENILE SYSTEMIC LUPUS ERYTHEMATOSUS IN PORTUGUESE CHILDREN}

W Castelão, H Canhão, C Resende, JE Fonseca, JC Teixeira Costa, JA Pereira Silva, M Viana Queiroz. Rheumatology Unit, Santa Maria Hospital, Lisbon, Portugal

10.1136/annrheumdis-2001.504 